\title{
Immediate Effect of Kinesio Taping on Knee Joint Proprioception after Anterior Cruciate Ligament Reconstruction
}

\author{
Azizati Rochmania ${ }^{1}$, Reni H. Masduchi' ${ }^{1}$, Dwikora N. Utomo ${ }^{2}$ \\ ${ }^{1}$ Departement of Physical Medicine and Rehabilitation, Dr. Soetomo Hospital \\ 2 Departement of Orthopedics and Traumatology, Dr. Soetomo Hospital - Airlangga University, \\ Surabaya, Indonesia
}

\begin{abstract}
Objectives : To evaluate the effect of KinesioTaping on knee joint proprioception of patient with reconstructed anterior cruciate ligament.

Methods: Randomized trial, cross-over study design, was done in Rehabilitation outpatient clinic, Soetomo General Hospital, Surabaya, on 9 isolated anterior cruciate ligament (ACL) patients, which has underwent ACL reconstruction procedure. Each patient will become control for themselves. Subjects were treated with standardized Kinesio Taping technique for anterior cruciate ligament injury in addition to standard rehabilitation program for anterior cruciate ligament reconstruction. Response to treatment was evaluated with two evaluations: 1) Joint position sense of the knee for predetermined angle $\left(30^{\circ}\right.$, $45^{\circ}$ and $\left.60^{\circ}\right)$ 2) Threshold to detect of passive knee motion on $90^{\circ}$ moving into extension. Measurements were taken two times within 3 days of interval, with and without Kinesio Taping application. Error of angular displacement of active angle reproduction (joint position sense) and threshold to detect of passive motion (TTDPM) were measured in three condition: before Kinesio Taping application, after Kinesio Taping application and without Kinesio Taping application.

Results : Nine patients (mean age $20.33 \pm 4.062$ y) who had anterior cruciate ligament reconstruction were included for this study. There were no other knee ligament injuries. There were significant different in active angle reproduction (joint position sense) at $30^{\circ}$ and $45^{\circ}$ extension between affected and unaffected knee ( $p=.030$ and $p=.015$ respectively). Kinesio Taping application showed significant effect in active angle reproduction at $30^{\circ}$ of knee extension $(p=0.028)$. There were no significant different in TTDPM between all condition.

Conclusions: Kinesio Taping application improves active angle reproduction (joint position sense) at $30^{\circ}$ of knee extension. There is no difference in joint position sense at $45^{\circ}$ and $60^{\circ}$ with Kinesio Taping application. There is no difference in TTDPM in all condition.
\end{abstract}

Keywords: Kinesio Taping, rehabilitation, knee joint proprioception, anterior cruciate ligament reconstruction.

\section{INTRODUCTION}

Lately the incidence of anterior cruciate

Received in March 2012 and accepted for published in April 2012.

Correspondence address : Azizati Rochmania, Faculty of Sport Education, University of Negeri Surabaya, Jl. Arif Rahman Hakim gg 5 no 585 Malang 65119. Email : niasyaf@yahoo.co.id ligament (ACL) tear is increasing. It was caused by increasing participation of society in sports especially sports with decelerating movement, cutting and changing direction movements such as basketball, soccer, and hand ball players. ACL tear is the most common injury of the knee joint ligaments. ${ }^{1,2}$ Almost half of all knee ligament injuries is due to ACL tear and it cause most of knee instability ${ }^{3,4}$, which may alter the function, destruct other joint structures which then 
can affect daily living activities and walking function. ${ }^{1,4-6}$ Some studies of ACL injuries subjects show alteration of proprioceptive function of the knee joints. ${ }^{7}$

ACL tear can affect the proprioceptive function and knee joint stability. Most of researches of knee with ACL tear show the decrease of proprioceptive function of the knee joint. ${ }^{4,6-14}$ One of the management of ACL tear is by the ACL reconstruction, in which tissue transplant will be planted to replace the damaged ACL. The ACL reconstruction is expected to replace the proprioceptive function of the knee joint which can repair the afferent input needed for knee stability and proprioceptive. A histological research proved the mechanoreceptor regeneration of the ACL tissue transplant, ${ }^{15}$ which is seen from the fourth week post reconstruction. ${ }^{16}$ Meanwhile, other researches showed the change of motor and sensory behavior after ACL reconstruction, which is suspected to be caused by lack of proprioceptive information due to ACL lesion and/or ACL substitution of the tissue transplant. ${ }^{4}$ Some ACL reconstruction techniques have been developed and were expected to replace the knee joint function. Nevertheless, the proprioceptive function alteration is still found on the midrange of knee joint range of motion $\left(40-60^{\circ}\right){ }^{6}$ The effect of ACL reconstruction on the knee joint proprioceptive function is still controversy.

Kinesio Taping (KT) is one of new methods developed by Dr. Kenzo Kaze, designed to decrease pain, improve performance, reeducate neuromuscular system, prevent injury, and improve lymph drainage, which can be used to support rehabilitation program and modulate physiological process. ${ }^{17-19} \mathrm{KT}$ is also able to improve proprioceptive system by normalising muscle tone, decrease pain, repair position and stimulate skin receptor. ${ }^{19}$ Some researches on KT application show the improvement of trunk flexion range of motion, ${ }^{20}$ improve medial vastus muscle activities, ${ }^{19}$ improve active range of motion of the limb, ${ }^{21}$ and reduce shoulder pain on abduction movement of the shoulder impingement patient. ${ }^{18}$

The effect of KT on the joint proprioceptive function is presumed due to the stimulation of skin receptor and joint which will influence the sensory nervous system and give feedback on the position and joint movement. Researches on the effect of KT on the joint proprioception are limited. Murray et al. ${ }^{22}$ studied the KT effect on the ankle joint proprioceptive function and concluded that KT can improve the proprioceptive function of the ankle joint on the $10^{\circ}$ plantarflexion angle of non-weight bearing position. While Halseth et al. ${ }^{23}$ concluded that the application of KT did not result in significant effect of the ankle joint proprioception.

Research to know the effect of KT on knee joint proprioceptive function post ACL reconstruction has not been done yet, which encouraged us to undergo this research.

\section{METHODS}

Samples are subjects with ACL tear post reconstruction who came to medical rehabilitation outpatient clinic, orthopedic, and sports clinic of the Dr. Soetomo Hospital, Surabaya. Study samples are post ACL tear reconstruction patients who fit the inclusion criteria post reconstruction of ACL tear until the desired amount of samples is met. The inclusion criterias are: (1) ACL tear patient who had undergone reconstruction, 6 to 8 weeks period post ACL reconstruction, (2) aged 16-35 years old, (3) have no limitation of knee joint range of motion, (4) have no sign of extended inflammation, (5) able to understand and follow the assessment instructions, (6) have not received proprioceptive exercise program, (7) willing to participate in the study by signing informed consent after clear explanation. Exclusion criterias are: (1) knee ligament injury except ACL, (2) knee pain with Visual Analogue Scale $>3$, (3) lower limb fractures, (4) central or peripheral neurological disorders.

Sample size in this study is according to sample size estimation for paired 2 samples hipothesis test. Sample size is 8 subjects for each group, with the same subjects will be cross-overed, so the amount of samples are 16 study subjects. We use consecutive sampling methods, where all subjects who came and filled the criteria will be included in the study, then randomized as control and treatment groups until the sample size needed was met. 
This is a controlled randomized clinical experimental trial with cross-over design, from February to April 2011. Research location is at the Medical Rehabilitation Installation policlinic of Dr. Soetomo Hospital, Surabaya. Ethical clearance is obtained from the Ethical Commission for basic/clinical science of the Dr. Soetomo Hospital Surabaya.

Study samples were divided into two groups, the A treatment group and the B control group; after the wash-out period, cross-over process was made that the A treatment group became the B' control group and the B control group became the A' treatment group. All study subjects received standard Kintesio Taping application for the ACL injury. All study subjects received standard rehabilitation program post ACL reconstruction.

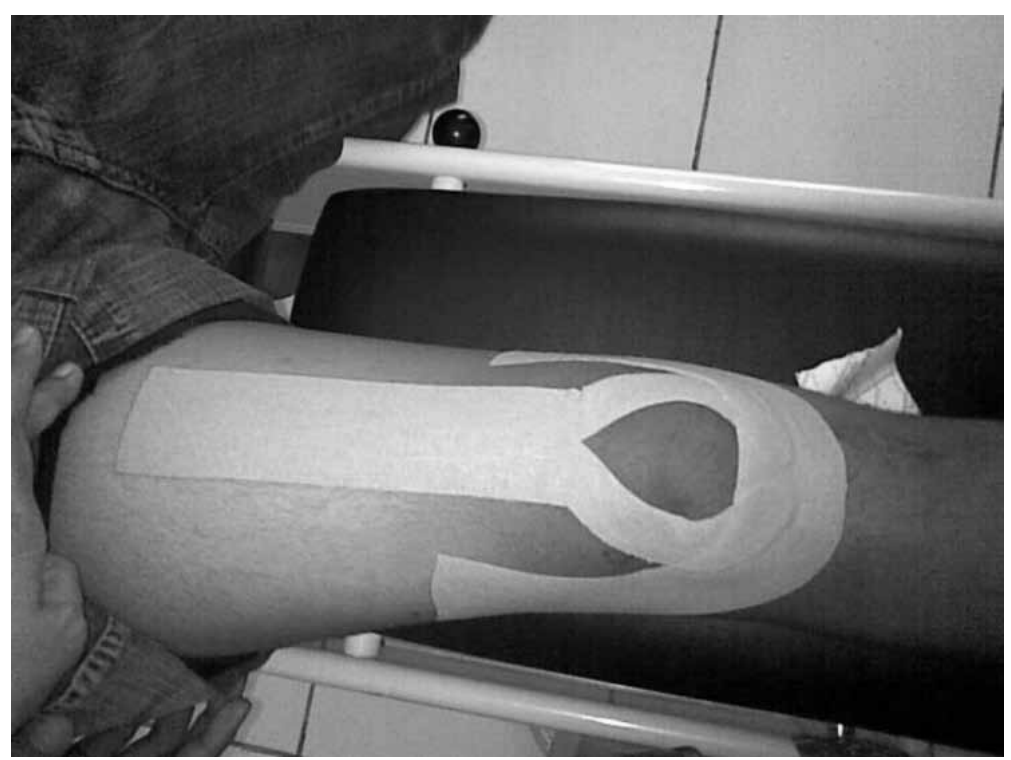

Figure 1 The KinesioTape application for ACL injury

The KT application for the ACL injury, both acute and post acute were using the $\mathrm{Y}$ superior quadriceps techniques from its origo to its insersion to facilitate the muscle contraction. For post acute phase, ligament correction was added which was modified and applicated from the tibial tuberosity to the medial and lateral epicondyles to limit the anterior translation of the tibia to femur. ${ }^{24}$

The study results parameter were using the mean value of joint position sense (JPS) and mean value of threshold to detection of passive movement (TTDPM). The JPS and TTDPM assessments were done in two visits to the Medical Rehabilitation Installation of the Dr. Soetomo Hospital, Surabaya with 3 days or more periods between the first visit and the second visit. The JPS and TTDPM assessments were done before and after the application of kinesio tape and without the application of kinesio tape in other visit.

The knee joint proprioceptive assessment can be done by using TTDPM or JPS or both of them. Severeal researches used JPS only ${ }^{6}$, 11, 14, 25-27 , TTDPM only ${ }^{4,7,13}$ or both., ${ }^{4,9,28-}$ 29 The effectivity of these methods are still controversial. Pap ${ }^{7}$ showed that assessment by TTDPM only was not enough to evaluate the proprioception of the knee with ACL disorder. While Reider ${ }^{8}$ concluded that TTDPM is a more trusted method than JPS to assess propioception before and after the ACL reconstruction. On the other hand, Anders ${ }^{25}$ said that JPS is an appropriate method for proprioceptive assessment of the knee joint.

Statistical test was done with SPSS 13.0 with significance level of $\mathrm{p}<0.05$. Data normality test was done by one sample KolmogorovSmirnov test. Parametric statistical test for ratio data was done by paired t-test. 
Figure 2. Diagram Flow of Trial

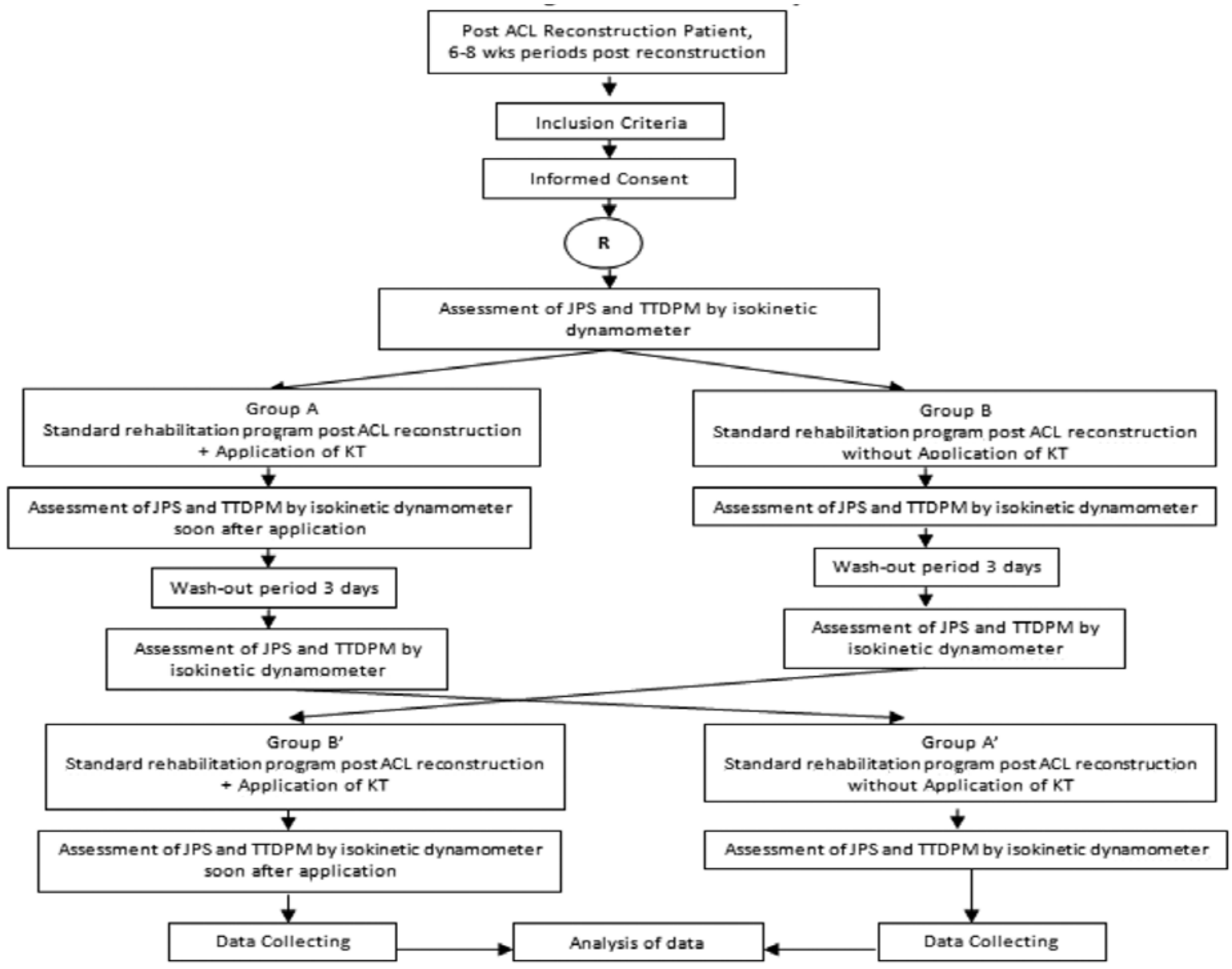

\section{RESULTS}

Total of study subjects are nine subjects, divided into two groups A and B. Group A received treatment on the first visit, and became control on the second visit. Group B became control on the first visit, and received treatment on the second visit. All subjects have through a washout period for three days or more between the first and the second visit, and all subjects became treatment group and control group. From nine study subjects, five subjects were from group A and four subjects were from group B. Of five subjects in group A, one subject was drop outm due to inability to fulfill the second assessment schedule for data collection. All subjects (four subjects) from group B fulfilled two assessment visits.

Demographical and clinical characteristics of study subjects was shown on table 1 . Mean age of study subjects was $20.33 \pm 4.062$ years old. Mean period post operation was $6.67 \pm 1.00$ weeks. Mean onset from injury to operation was $17.22 \pm 15.344$ weeks. Subjects whose affected knee was in their right knee were five subjects and in the left knee were 4 subjects. ACL reconstruction were done by arthroscopy technique with hamstring or patellar tendon graft in all patients. All subjects have not received proprioceptive exercise program of the knee joint. 
Table 1. General characteristics of study subjects

\begin{tabular}{lc}
\hline \multicolumn{1}{c}{ Characteristict } & Mean \\
\hline Age (years) & $20.33 \pm 4.062$ \\
Post operation period (weeks) & $6.67 \pm 1.00$ \\
Affected knee (right/left) & $5 / 4$ \\
Onset of injury to operation (weeks) & $17.22 \pm 5.344$ \\
\hline
\end{tabular}

Mean JPS of non affected knee showed significant difference compared to affected knee in the control group at the angle of $30^{\circ}$ and $45^{\circ}$ (table 2). Mean JPS and TTDPM of non affected knee compared to affected knee before treatment showed no significant difference (table 3). Mean JPS at tha angle of $30^{\circ}, 45^{\circ}$ and TTDPM of non affected knee compared to affected knee after treatment showed no significant difference (table 4). Mean JPS and TTDPM affected knee before treatment compared to affected knee after treatment showed no significant difference (table 5). Mean JPS and TTDPM affected knee in control group compared to affected knee before treament showed no significant difference (table 6). Mean JPS at $30^{\circ}$ angle of affected knee in control group compared to affected knee after treatment showed significant difference (table 7).

Table 2. Difference of mean JPS and TTDPM between non affected knee and affected knee of control group

\begin{tabular}{cccc}
\hline Parameter & Non affected knee & $\begin{array}{c}\text { Affected knee } \\
\text { (control) }\end{array}$ & $\mathrm{p}^{*}$ \\
\hline Total subjects & 8 & 8 & - \\
JPS at angle $30^{\circ}$ & $2.28 \pm 0.897$ & $4.20 \pm 1.699$ & 0.030 \\
JPS at angle $45^{\circ}$ & $2.91 \pm 1.630$ & $6.24 \pm 3.091$ & 0.015 \\
JPS at angle $60^{\circ}$ & $4.24 \pm 2.210$ & $5.71 \pm 2.732$ & 0.358 \\
TTDPM (seconds) & $4.60 \pm 2.848$ & $4.50 \pm 1.907$ & 0.831 \\
\hline
\end{tabular}

Note: Value are mean \pm standard deviation (SD)

* $p$ value show probability or significance level with paired t-test

Table 3. Difference of mean JPS and TTDPM between non affected knee and affected knee before treatment

\begin{tabular}{cccc}
\hline Parameter & Non affected knee & $\begin{array}{c}\text { Affected knee before } \\
\text { treatment }\end{array}$ & $p^{*}$ \\
\hline Total subjects & 9 & 9 & - \\
JPS at angle $30^{\circ}$ & $2.55 \pm 1.153$ & $3.62 \pm 2.182$ & 0.212 \\
JPS at angle $45^{\circ}$ & $3.51 \pm 2.363$ & $4.76 \pm 3.167$ & 0.402 \\
JPS at angle $60^{\circ}$ & $4.18 \pm 2.076$ & $6.29 \pm 4.94$ & 0.180 \\
TTDPM (seconds) & $4.39 \pm 2.742$ & $5.02 \pm 4.336$ & 0.639 \\
\hline
\end{tabular}

Note: Value are mean \pm standard deviation (SD)

* $p$ value show probability or significance level with paired t-test 
Table 4. Difference of mean JPS and TTDPM between non affected knee and affected knee after treatment

\begin{tabular}{cccc}
\hline Parameter & Non affected knee & $\begin{array}{c}\text { Affected knee before } \\
\text { treatment }\end{array}$ & $p^{*}$ \\
\hline Total subjects & 9 & 9 & - \\
JPS at angle $30^{\circ}$ & $2.55 \pm 1.153$ & $2.29 \pm 0.977$ & 0.633 \\
JPS at angle $45^{\circ}$ & $3.51 \pm 2.363$ & $3.84 \pm 1.536$ & 0.759 \\
JPS at angle $60^{\circ}$ & $4.18 \pm 2.076$ & $6.58 \pm 3.320$ & 0.040 \\
TTDPM (seconds) & $4.39 \pm 2.742$ & $4.21 \pm 3.142$ & 0.741 \\
\hline
\end{tabular}

Note: Value are mean \pm standard deviation (SD)

* $p$ value show probability or significance level with paired t-test

Table 5. Mean JPS and TTDPM of affected knee in treatment group before and after treatment

\begin{tabular}{cccc}
\hline Parameter & Non affected knee & $\begin{array}{c}\text { Affected knee after } \\
\text { treatment }\end{array}$ & $p^{*}$ \\
\hline Total subjects & 9 & 9 & - \\
JPS at angle $30^{\circ}$ & $3.62 \pm 2.182$ & $2.29 \pm 0.977$ & 0.097 \\
JPS at angle $45^{\circ}$ & $4.76 \pm 3.167$ & $3.84 \pm 1.536$ & 0.472 \\
JPS at angle $60^{\circ}$ & $6.29 \pm 4.94$ & $6.58 \pm 3.320$ & 0.808 \\
TTDPM (seconds) & $5.02 \pm 4.336$ & $4.21 \pm 3.142$ & 0.540 \\
\hline
\end{tabular}

Note: Value are mean \pm standard deviation (SD)

* $p$ value show probability or significance level with paired t-test

Table 6. Comparison of mean JPS and TTDPM of affected knee (control) and affected knee before treatment

\begin{tabular}{cccc}
\hline Parameter & Non affected knee & $\begin{array}{c}\text { Affected knee before } \\
\text { treatment }\end{array}$ & $p^{*}$ \\
\hline Total subjects & 8 & 8 & - \\
JPS at angle $30^{\circ}$ & $4.20 \pm 1.699$ & $3.20 \pm 1.901$ & 0.361 \\
JPS at angle $45^{\circ}$ & $6.24 \pm 3.091$ & $5.19 \pm 3.092$ & 0.148 \\
JPS at angle $60^{\circ}$ & $5.71 \pm 2.732$ & $6.70 \pm 5.115$ & 0.658 \\
TTDPM (seconds) & $4.50 \pm 1.907$ & $5.38 \pm 4.491$ & 0.578 \\
\hline
\end{tabular}

Note: Value are mean \pm standard deviation (SD)

* $p$ value show probability or significance level with paired t-test 
Table 7. Comparison of mean JPS and TTDPM of affected knee (control) and affected knee after treatment

\begin{tabular}{cccc}
\hline Parameter & Affected knee (control) & $\begin{array}{c}\text { Affected knee } \\
\text { after treatment }\end{array}$ & $p^{*}$ \\
\hline Total subjects & 8 & 8 & - \\
JPS at angle $30^{\circ}$ & $4.20 \pm 1.699$ & $2.20 \pm 1.006$ & 0.028 \\
JPS at angle $45^{\circ}$ & $6.24 \pm 3.091$ & $3.83 \pm 1.641$ & 0.107 \\
JPS at angle $60^{\circ}$ & $5.71 \pm 2.732$ & $6.58 \pm 3.549$ & 0.664 \\
TTDPM (seconds) & $4.50 \pm 1.907$ & $4.25 \pm 3.356$ & 0.773 \\
\hline
\end{tabular}

Note: Value are mean \pm standard deviation (SD)

* $p$ value show probability or significance level with paired t-test

\section{DISCUSSION}

Elastic therapeutic tape called Kinesio Tape was once introduced by its founder, Dr. Kenzo Kaze from Japan in 1973. Lately the use of Kinesio Taping (KT) has increased after its application in the Seoul Olympic 1988 and Beijing Olimpic 2008 by several volley ball and cycling athletes. ${ }^{24,30}$ Some researches have been done to assess the effectivity of KT application, and most of these supported the effectivity of $\mathrm{KT}^{31-}$ ${ }^{37}$, although several researches did not support the improvent also. ${ }^{23,38}$

This study results showed the statistical difference of JPS at angle $30^{\circ}$ and $45^{\circ}$ of affected knee in the control group compared to non affected side. There was no significant difference of JPS at angle $60^{\circ}$ and TTDPM compared to non affected knee. This was similar with some studies of ACL reconstruction subjects. Bonfim et al. ${ }^{4}$ concluded that there was still proprioceptive deficit in post ACL reconstruction subjects at 12 to 30 months periods post operation. Mou-wang ${ }^{26}$ reported JPS deficit of post ACL reconstruction subjects at 6 months periods post surgery. Fremerey et al. 6 reported JPS deficit at 3 months post operation at the knee extension position $\left(0^{\circ}-20^{\circ}\right)$, mid-range $\left(40^{\circ}-60^{\circ}\right)$ and flexion $\left(80^{\circ}-100^{\circ}\right)$, yet there was still a JPS deficit at the mid-range position until three years post reconstruction.

There was no statistical difference of JPS and TTDPM of affected knee before treatment compared to JPS and TTDPM after treatment (table 5). This study is the first study of KT effect on the proprioceptive function done in post ACL reconstruction. Some studies of taping on joint propriocepton have been done with similar results. Halseth et al. ${ }^{39}$ studied with cross-over design pre-post of 30 healthy subjects and concluded there was no significant difference of JPS in non-taped ankle compared to taped ankle in the same subjects. They did not mention the period between the first and the second assessment. The period of KT application until the assessment is five minutes. Other study related with ankle joint proprioception was done by Murray et al. who compared the JPS of non-taped ankle condition, with white athletic tape and with KT in 26 healthy subjects and concluded that KT can improve JPS at the angle of $10^{\circ}$ plantar flexion. Duration between JPS assessment in each condition was 3 minutes. ${ }^{22}$ The study of Halseth et al. and Murray et al. were different on the study methodology. This could result in different study result between both. This study use almost similar methodology with Halseth, with cross-over design pre-post treatment. The difference was on the subjects (healthy subjects) with no joint instability, that made no statistical and clinical difference before and after treatment, due to normal value on the early assessment.

Although there was no statistical difference of JPS and TTDPM after treatment compared to JPS and TTDPM before treatment, there was significant clinical difference. Mean JPS at angle $30^{\circ}$ and $45^{\circ}$ after treatment was clinically 
decreased (improved) compared to mean JPS at angle $30^{\circ}$ and $45^{\circ}$ before treatment (table 5). This was supported by the comparison result of JPS at angle $30^{\circ}$ on affected side without treatment (control) compared with JPS at angle $30^{\circ}$ on affected side after treatment which showed significant statistical difference (table 7), while JPS at angle $45^{\circ}$ affected knee without treatment (control) had clinical difference compared with affected knee after treatment. This was similar with Callaghan et al., who concluded the accuracy improvement of JPS active and passive in poor proprioceptive ability subject group, although no significant statistical difference on taping condition compared with non taping condition.

There are severeal theories of how KT affects the joint prorioceptive function. First, KT stimulates the mechanoreceptor of skin and joint that give information input to the central nervous system (sensorimotor system) about position of joint and joint movement which will result in definite joint movement. Second, KT improves the biomechanics and joint alignment by stimulation of the skin and muscle receptors (reflex cycle) that will equalize the agonist and antagonist muscles and increase awareness of joint movement. Third, KT stimulates the muscle receptor through the $\gamma$-muscle spindle system which manage degree of stiffness and muscle tone and give feedback to the central nervous system of definite joint movement. ${ }^{24}$, ${ }^{40}$ The KT application for ACL injury will stimulate quadriceps muscle which is important for anterior translation of the tibia, thus will affect the ACL tension. The I strip application will also decrease anterior translation of the tibia. Besides that, KT will give neuromuscular training to the reflex cycle and sensorimotor system through the stimulation of joint and skin mechanoreceptor. Direct effect of KT application to the skin tissue and joint (skin and joint mechanoreceptor) has not been studied yet.

The limitations of this study are: (1) the learning effect on JPS and TTDPM assessments can result in measurement bias that is subject bias, (2) isokinetic dynamometer machine used in this study is not moving automatically on TTDPM assessment, that will make the subjects realize when the machine will be started to move.
This can result ini measurement bias that is tool bias, (3) the research condition that involved outpatient subjects cause the researcher unable to control daily activities of subjects which include proprioceptive exercise of knee joint, that can result in subject bias.

\section{CONCLUSIONS}

The KT application of knee joint patients with post ACL tear reconstruction cannot improve JPS at angle $45^{\circ}$ and at angle $60^{\circ}$. The KT application of knee joint patients with post ACL tear reconstruction cannot improve TTDPM. There was improvement of JPS at angle $30^{\circ}$ of knee post ACL tear reconstruction after the application of KT compared with JPS of knee post ACL tear reconstruction without the application of KT. There was no difference of TTDPM of knee post ACL tear reconstruction after the application of KT compared with TTDPM of knee post ACL tear reconstruction without the application of KT. There was JPS deficit at angle $30^{\circ}$ and $45^{\circ}$ of patient's knee post ACL reconstruction.

\section{REFERENCES}

1. Feller JA, Webster KE. Proprioception and Anterior Cruciate Ligament Reconstruction. In: Prodromos CC, editor. The Anterior Cruciate Ligament: Reconstruction and Basic Science. 1st edition Philadelphia: Saunders Elsevier; 2008. p. 535-9.

2. Milner CE. Functional Anatomy for Sport and Exercise: Quick Reference. New York: Routledge; 2008 [cited 2009.

3. DeFranco MJ, Bernard R. Bach J. A Comprehensive Review of Partial Anterior Cruciate Ligament Tears. J Bone Joint Surg Am 2009;91:198-208.

4. Bonfim TtR, Paccola CAJ, Barela JA. Proprioceptive and Behavior Impairments in Individuals With Anterior Cruciate Ligament Reconstructed Knees. Arch Phys Med Rehabil. 2003. August;84:1217-23.

5. Hubbell JD, Schwartz E. Anterior Cruciate Ligament Injury. 2006 [updated Mar 
7, 2006; cited 200919 May]; Available from: http://emedicine.medscape.com/ sports_medicine\#knee.

6. Fremerey RW, Lobenhoffer P, Zeichen J, Skutek M, Bosch U, Tscherne H. Proprioception after rehabilitation and reconstruction in knees with deficiency of the anterior cruciate ligament. British Editorial Society of Bone and Joint Surgery. [A Prospective, longitudinal study ]. 2000 August;82-B (6):801-6.

7. Pap G, Machner A, Nebelung W, Awiszus F. Detailed analysis of proprioception in normal and ACL-deficient knees. Bone Joint Surg [Br]. 1999;81.

8. Reider B, Arcand M, Diehl L, K Mroczek, Abulencia A, Stroud C, et al. Proprioception of the knee before and after anterior cruciate ligament reconstruction. Arthroscopy: The Journal of Arthroscopic and Related Surgery. 2003 19(1):2-12.

9. Skinner HB, Barrack RL. Joint position sense in the normal and pathologic knee joint Journal of emg and kinesiology. 2004;1(3):180-90

10. Fridén T, Roberts D, Ageberg E, Waldén M, Zätterström R. Review of knee proprioception and the relation to extremity function after an anterior cruciate ligament rupture. J Orthop Sports Phys Ther. 2001;31(10):567-76.

11. Carter ND, Jenkinson TR, Wilson D, Jones DW, Torode AS. Joint position sense and rehabilitation in the anterior cruciate ligament deficient knee. Br J Sports Med. 1997;31:209-12.

12. Beard DJ, Kyberd PJ, Fergusson CM, Dodd CAF. Proprioception after rupture of the anterior cruciate ligament: an objective indication of the need for surgery? J Bone Joint Surg [Br] 1993 .75B:311-5.

13. Barrack RL, Skinner HB, Buckley SL. Proprioception in the anterior cruciate deficient knee Am J Sports Med 1989;17(1):1-6.

14. Katayama M, Higuchi H, Kimura M, Kobayashi A, Hatayama K, Terauchi M, et al. Proprioception and performance after anterior cruciate ligament rupture International Orthopaedics 1997;28(5):278-81.

15. Ergen E, Ulkar B. Proprioception and Coordination. In: Frontera WR, Hering SA, Micheli LJ, Silver JK, editors. Clinical Sports Medicine; Medical Management and Rehabilitation. 1st edition. Philadelphia: Saunders Elsevier; 2007. p. 237-45.

16. Shimizu T, TakahashiT, WadaY,TanakaM, Morisawa Y, Yamamoto H. Regeneration process of mechanoreceptors in the reconstructed anterior cruciate ligament. Arch Orthop Trauma Surg. [Original Article]. 1999;119:405-9.

17. Cristoveanu I. What is Kinesio Taping $®$ ? Ottawa; [cited on March 25 2010]. Available from: www.holisticclinic.ca.

18. Thelen MD, Dauber JA, Stoneman PD. The Clinical Efficacy of Kinesio Tape for Shoulder Pain: A Randomized, Double-Blinded, Clinical Trial. J Orthop Sports Phys Ther. [Research report]. 2008;38(7):389-95.

19. Slupik A, Dwornik M, Bialoszewski D, Zych E. Effect of kinesiotaping on bioelectrical activity of vastus medialis muscle. Ortopedia Traumatologia Rehabilitacja. [Preliminary Report]. 2007;9(6):644-51.

20. Yoshida A, Kahanov L. The effect of kinesio taping on lower trunk range of motions. Res Sports Med. 2007 AprJun;15(2):103-12.

21. Murray HM. Effects of Kinesio Taping on Muscle Strength after ACL-Repair. Journal of Orthopedic and Sports Physical Therapy. 2000;30(1).

22. Murray HM, Husk LJ. Effect of Kinesio Taping ${ }^{\circledR}$ on Proprioception in the Ankle. Journal of Orthopedic and Sports Physical Therapy. 2001;31(1):A-37.

23. Halseth T, McChesney JW, DeBeliso M, Vaughn R, Lien J. The Effects Of Kinesio Taping On Proprioception At The Ankle. Journal of Sports Science and Medicine. [Research article]. 2004;3:1-7.

24. Kase K, Wallis J, Kase T. Clinical Therapeutic Application of The Kinesio 
Taping Method. Tokyo: Ken Ikai Co.Ltd.; 2003; [cited on March 25 2010]. Available from: http://www.kinesiotaping.com/.

25. Anders JO, Venbrocks RA, Weinberg M. Proprioceptive skills and functional outcome after anterior cruciate ligament reconstruction with bone-tendonbone graft International Orthopaedics. [Original paper]. 2008;32:627-33.

26. Mou-wang Z, LiG, Ya-ping C, Chang-long Y, Ying-fang A, Hong-shi H, et al. Factors affecting proprioceptive recovery after anterior cruciate ligament reconstruction. Chin Med J 2008;121(22):2224-8.

27. Mir S, Hadian M, Talebian S, Nasseri N. Functional assessment of knee joint position sense following anterior cruciate ligament reconstruction. $\mathrm{Br} \mathrm{J}$ Sports Med 2008;Apr, 42(4):300-3.

28. Friden T, Roberts D, Zaitterstrom R, Lindstrand A, Moritz U. Proprioception in the nearly extended knee: Measurements of position and movement in healthy individuals and in symptomatic anterior cruciate ligament injured patients. Knee Surg, Sports Traumatol, Arthroscopy. 1996;4:217-24.

29. Grob KR, Kuster MS, Higgins SA, Lloyd DG, Yata H. Lack of correlation between different measurements of proprioception in the knee. J Bone Joint Surg [Br]. 2002;84-B:614-8.

30. UK K. Brief History of Kinesio Tex Taping. United Kingdom: Kinesio UK; 2009 [cited 201025 March]; Available from: http://www.kinesiotaping.co.uk/ index.jsp.

31. Slupik A, Dwornik M, Bialoszewski D, Zych E. Effect of kinesio taping on bioelectrical activity of vastus medialis muscle. Preliminary report. Ortopedia Traumatologia Rehabilitacja. [Original Article]. 2007;9(6):644-51.
32. Yasukawa A, Patel P, Sisung. C. Pilot study: Investigating the effects of Kinesio Taping ${ }^{\circledR}$ in an acute pediatric rehabilitation setting. American Journal of Occupational Therapy. [Pilot study]. 2006;60:104-10.

33. Yoshida A, Kahanov L. The Effect Of Kinesio Taping On Lower Trunk Range of Motion. . Research in Sports Medicine. [Research Article]. 2007;15:103-12.

34. Thelen M, Dauber J, Stoneman P. The Clinical Efficacy of Kinesio Tape for Shoulder Pain: A Randomized, DoubleBlinded, Clinical Trial. . Journal of Orthopaedic \& Sports Physical Therapy. [Research Report]. 2008;38(7):389-95.

35. Murray. H. Effects of Kinesio Taping on Muscle Strength after ACL-Repair. Journal of Orthopedic and Sports Physical Therapy. 2000;30(1).

36. Osterhues. D. The use of Kinesio Taping in the management of traumatic patella dislocation. A case study. Physiotherapy Theory and Practice. [Case report]. 2004;20:267-70.

37. Hsu Y, Chen W, Lin H, Wang W, Shih. Y. The effects of taping on scapularkinematics and muscle performance in baseball players with shoulder impingement syndrome. Jour Electromyogr Kinesiol. 2009;19(6):1092-9.

38. Fu T, Wong A, Pei Y, Wu K, Chou S, Lin. Y. Effect of Kinesio taping on muscle strength in athletes-a pilot study. J Sci Med Sport sport med aussie 2008 Apr;11(2):198-201.

39. Halseth T, McChesney J, DeBeliso M, Vaughn R, Lien J. The Effect of Kinesio taping on proprioception at the ankle Journal of Sports Science and Medicine. [Research Article]. 2004;3:1-7.

40. Hancock D. Scientific Explanation of Kinesio Tex Tape. 2008. 